\title{
Hereditary hyperhomocysteinemia associated with nephrotic syndrome complicated by artery thrombosis and chronic thromboembolic pulmonary hypertension: A case report
}

\author{
Paolo Ruggeri1, Federica Lo Bello1, Francesco Nucera1, Michele Gaeta², Francesco Monaco², \\ Gaetano Caramori1, Giuseppe Girbino1
}

\author{
1 Pneumology Operating Unit, Department of Biomedical and Dental Sciences and of Morphological \\ and Functional Images, University of Messina \\ 2 Diagnostic Imaging Unit, Department of Biomedical and Dental Sciences and of Morphological \\ and Functional Images, University of Messina \\ 3 Thoracic Surgery Unit, Department of Biomedical and Dental Sciences and of Morphological \\ and Functional Images, Università di Messina, Italy
}

\begin{abstract}
We present here the case of a 30 -year-old man with a long term history of nephrotic syndrome (NS) who developed an episode of acute left main pulmonary artery thrombosis complicated by a lung abscess. During the hospital admission was also identified a concomitant hyperhomocysteinemia. After an atypical resection of the left upper pulmonary lobe and the starting of long term anticoagulation the patient was discharged but
\end{abstract}

Corresponding Author: Paolo Ruggeri, Unità Operativa Complessa di Pneumologia, Dipartimento di Scienze Biomediche, Odontoiatriche e delle Immagini Morfologiche e Funzionali (BIOMORF), Università di Messina, Italy. Tel. +39.090.2212002 - Fax: +39.090.2934157. E-mail: plrugger@unime.it

Key words: Chronic thromboembolic pulmonary hypertension; pulmonary embolism; nephrotic syndrome; hyperhomocysteinemia.

Acknowledgments: We thank Ms Franca Mollica and Mr Angelo Zodda for their administrative support.

Contributions: PR contributed substantially to conception, design and drafting of case report manuscript; FL, MG, involved in data acquisition; $\mathrm{AB}, \mathrm{MG}$, involved in imaging acquisition; GG, FM, GC, equally involved in critically revising the manuscript.

Consent for publication: Written informed consent was obtained from the patient for publication of this case report and any accompanying images. A copy of the written consent is available for review by the Editor of this journal.

Conflict of interest: The authors declare no conflict of interest.

Received for publication: 7 August 2017

Accepted for publication: 5 November 2017

(C) Copyright P. Ruggeri et al., 2017

Tipografia PI-ME Editrice, Italy

Monaldi Archives for Chest Disease 2017; 87: 880

doi: 10.4081/monaldi.2017.880

This article is distributed under the terms of the Creative Commons Attribution Noncommercial License (by-nc 4.0) which permits any noncommercial use, distribution, and reproduction in any medium, provided the original author(s) and source are credited. did not attend the planned follow up visits until one year later when he was seen again for severe dyspnea and exercise intolerance. At this time chronic thromboembolic pulmonary hypertension (CTEPH) was diagnosed by lung perfusion scintigraphy and right heart catheterization. He initially refused the surgical treatment but, after six months, for the presence of worsening dyspnea was referred for bilateral pulmonary endarterectomy followed by a cardio-thoracic rehabilitation program. After a follow-up of seven years the patient is alive and in stable conditions.

NS and hyperhomocysteinemia are both known risk factors for pulmonary embolism (PE), but their association with CTEPH is extremely rare. We discuss here the possible mechanisms linking these conditions. CTEPH must be suspected in any patient with NS, with or without hyperhomocysteinemia, and unexplained dyspnea.

\section{Introduction}

Thromboembolism is one of the major complications of nephrotic syndrome (NS) [1]. In particular, the presence of pulmonary artery thrombosis is often fatal [2]. Hyperhomocysteinemia is another accepted risk factor for pulmonary thromboembolism [3]. Chronic thromboembolic pulmonary hypertension (CTEPH) is a rare condition presenting in $2-4 \%$ of patients after acute pulmonary embolism but characterized by significant morbidity and mortality [4,5]. The association of NS and hyperhomocysteinemia with CTEPH is extremely rare.

\section{Case Report}

The case concerns a 30 -year-old (height $160 \mathrm{~cm}$, weight $60 \mathrm{Kg}$, body mass index $23 \mathrm{Kg} / \mathrm{m}^{2}$ ) Caucasian man, medical doctor, who presented at the emergency department of our University Hospital of Messina, Italy (www.polime.it) for the presence by 30 days of persistent dry cough associated in the last 7 days with exercise-induced dyspnea and bilateral pitting edema of the ankles. He was a current smoker of 3 pack-years, with of a history of minimal change nephrotic syndrome diagnosed (with a kidney biopsy) 20 years before the presentation and treated with low dose oral glucocorticoid (5 $\mathrm{mg}$ daily of prednisone equivalent) therapy from childhood. He was under regular treatment with diuretic ( $25 \mathrm{mg}$ once daily furosemide) and proton pump inhibitor (20 mg once daily of omeprazole) for systemic arterial hypertension and gastroesophageal reflux diagnosed 5 years before the presentation. 
One month before the current admission he had been treated intramuscularly for seven days at home by his General Practitioner with ceftriaxone (1 gram/once daily) for the presence of cough with yellow sputum, diffuse thoracic pain and fever $\left(37.5^{\circ} \mathrm{C}\right)$. At the admission, the patient presented with dyspnea (Borg scale 4) and oxygen desaturation (92\% when breathing room air). Blood gas test on room air was: $\mathrm{pH}$ 7.50, PaO2 60 mmHg; PaCO2 35 mmHg, HCO3- 28,5 mmol/L, BE + 4,6, Sat $93 \%$; Physical examination of the chest revealed only the presence of an hypophonesis in the left upper lobe. No other physical signs outside the chest were pathological. An x-ray of the chest showed the presence of a cavitated mass (10 $\mathrm{cm}$ of diameter) located in the upper left lobe with a frank air-fluid level (Figure 1). A computed tomography (CT) scan of the chest, performed before and after the administration of contrast medium, confirmed the presence of an excavated lesion in the upper left lobe of the lungs associated to the partial occlusion of the left main pulmonary artery containing a thrombus inside the lumen (Figure 1). These lesions were interpreted as a pulmonary infarction with a superimposed lung abscess secondary to left main pulmonary artery thrombosis. Immediately the patient was placed on twice daily enoxaparin ( $1 \mathrm{mg} / \mathrm{Kg})$. A duplex ultrasonography of the venous system of the lower legs was normal. The pathological routine laboratory tests are shown in Table 1. The most relevant abnormality was the presence of hyperhomocysteinemia with an homozygous T-variant of the common methylenetetrahydrofolate reductase (MTHFR) $677 \mathrm{C} \rightarrow \mathrm{T}$ polymorphism in the MTHFR gene. The lung abscess did not improve despite 15 days of treatment with adequate empiric wide spectrum antibiotic treatment (piperacillin/tazobactam $3.375 \mathrm{~g}$ IV every 6 hours). For this reason, the thoracic surgeon performed an atypical resection of the left upper pulmonary lobe. At the hospital discharge, after 21 days from his admission, the patient was in stable conditions with only residual exercise dyspnea (Borg scale 2) but without cough, chest pain, fever and/or peripheral edema. At the discharge he was under regular treatment with warfarin (with a target INR of 2.0-3.0) together with his previous regular pharmacological treatment (oral prednisone $5 \mathrm{mg}$ and furosemide $25 \mathrm{mg}$, both once daily). The patient did not attend our clinic for the planned three and six months follow-up visits but he presented spontaneously at our clinic again $\sim 12$ months after his hospital discharge reporting worsening exercise dyspnea (Borg scale 5). The
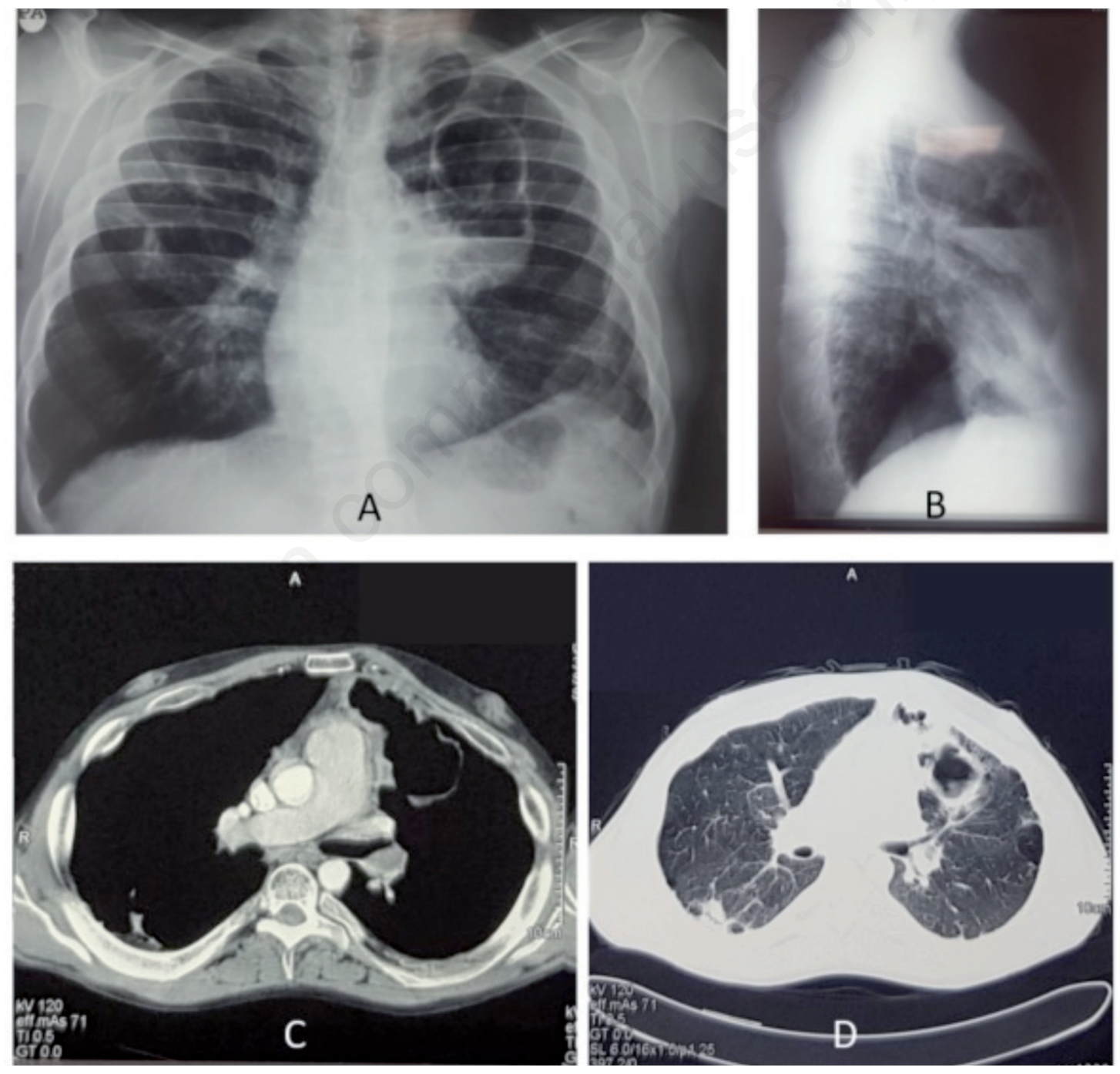

Figure 1. A,B) Posteroanterior and lateral chest $\mathrm{x}$-ray at presentation showed the presence of a cavitated mass $(10 \mathrm{~cm}$ of diameter) located in the upper left lobe with a frank air-fluid level. C,D) Computed tomography (CT) scan of the chest, performed before and after the administration of contrast medium, confirmed the presence of an excavated lesion in the upper left lobe of the lungs associated to the partial occlusion of the left main pulmonary artery containing a thrombus inside the lumen. 
Table 1. Summary of the clinical and laboratory parameters.

\begin{tabular}{|c|c|c|c|}
\hline \multicolumn{4}{|l|}{ Clinical parameters } \\
\hline Parameters & $\begin{array}{l}\text { Before atypical pulmonary } \\
\text { resection }\end{array}$ & $\begin{array}{l}\text { Before pulmonary } \\
\text { endarterectomy }\end{array}$ & $\begin{array}{l}\text { After pulmonary endarterectomy } \\
\text { (three months follow-up) }\end{array}$ \\
\hline Blood sistolic pressure & $120 \mathrm{mmHg}$ & $100 \mathrm{mmHg}$ & $120 \mathrm{mmHg}$ \\
\hline Blood diastolic pressure & $80 \mathrm{mmHg}$ & $70 \mathrm{mmHg}$ & $80 \mathrm{mmHg}$ \\
\hline Respiratory rate & 23/min & $25 / \mathrm{min}$ & $20 / \mathrm{min}$ \\
\hline Pulse rate & $92 / \mathrm{min}$ & $95 / \mathrm{min}$ & $85 / \mathrm{min}$ \\
\hline Oxigen saturation ${ }^{\circ}$ & $92 \%$ (room air) & $93 \%$ & $95 \%$ \\
\hline Axillary temperature & $37.5 \mathrm{C}^{\circ}$ & $36.5 \mathrm{C}^{\circ}$ & $36.2 \mathrm{C}^{\circ}$ \\
\hline \multicolumn{4}{|c|}{ Arterial blood gases analysis, performed with the patient breathing room air } \\
\hline Parameters & $\begin{array}{l}\text { Before atypical pulmonary } \\
\text { resection }\end{array}$ & $\begin{array}{l}\text { Before pulmonary } \\
\text { endarterectomy }\end{array}$ & $\begin{array}{l}\text { After pulmonary endarterectomy } \\
\text { (three months follow-up) }\end{array}$ \\
\hline $\mathrm{pH}(7.35-7.45)$ & 7.50 & 7.49 & 7.38 \\
\hline $\mathrm{PaCO} 2(35-45 \mathrm{mmHg})$ & $35 \mathrm{mmHg}$ & $30.7 \mathrm{mmHg}$ & $38 \mathrm{mmHg}$ \\
\hline $\mathrm{PaO} 2(80-100 \mathrm{mmHg})$ & $60 \mathrm{mmHg}$ & $68.7 \mathrm{mmHg}$ & $75 \mathrm{mmHg}$ \\
\hline Serum bicarbonates $(22-26 \mathrm{mmol} / \mathrm{L})$ & $28.5 \mathrm{mmol} / \mathrm{L}$ & $25.3 \mathrm{mmol} / \mathrm{L}$ & $23.4 \mathrm{mmol} / \mathrm{L}$ \\
\hline $\mathrm{SaO} 2(94 \%-100 \%)$ & $93.5 \%$ & $94.5 \%$ & $96 \%$ \\
\hline \multicolumn{4}{|l|}{ Laboratory parameters } \\
\hline Parameters & $\begin{array}{l}\text { Before atypical pulmonary } \\
\text { resection }\end{array}$ & $\begin{array}{l}\text { Before pulmonary } \\
\text { endarterectomy }\end{array}$ & $\begin{array}{c}\text { After pulmonary endarterectomy } \\
\text { (three months follow-up) }\end{array}$ \\
\hline Serum CRP (0-0.50) & $7.10 \mathrm{mg} / \mathrm{dl}$ & $2.5 \mathrm{mg} / \mathrm{dl}$ & $\mathrm{Nd}$ \\
\hline WBC (4500-9000) & $10.400 \mathrm{~mm} 3$ & $8.500 \mathrm{~mm} 3$ & $\mathrm{Nd}$ \\
\hline Platelets (150000-350000) & $429.000 \mathrm{~mm} 3$ & $380.000 \mathrm{~mm} 3$ & $\mathrm{Nd}$ \\
\hline Total plasma proteins (normal range) & $4.6 \mathrm{~g} / \mathrm{dL}$ & $5.6 \mathrm{~g} / \mathrm{dL}$ & $\mathrm{Nd}$ \\
\hline Albumin $(53 \%-65 \%)$ & $2.44 \mathrm{~g} / \mathrm{dL}(40.59 \%)$ & $3.5 \mathrm{~g} / \mathrm{dL}$ & $\mathrm{Nd}$ \\
\hline $\begin{array}{l}\text { Homocysteinemia } \\
(5-9 \mu \mathrm{mol} / \mathrm{L})\end{array}$ & $70 \mu \mathrm{mol} / \mathrm{L}$ & & \\
\hline \multicolumn{4}{|l|}{ Cardiac function tests } \\
\hline Left ejection fraction (echocardiography) & $55 \%$ & $60 \%$ & $62 \%$ \\
\hline $\begin{array}{l}\text { sPAP (echocardiography) } \\
(15-30 \mathrm{mmHg})\end{array}$ & $40-45 \mathrm{mmHg}$ & $70 \mathrm{mmHg}$ & $35 \mathrm{mmHg}$ \\
\hline $\begin{array}{l}\text { mPAP } \\
(9-18 \mathrm{mmHg})\end{array}$ & Nd & $46 \mathrm{mmHg}$ & $20.7 \mathrm{mmHg}$ \\
\hline $\begin{array}{l}\text { Pulmonary resistance } \\
\left(80-240 \text { dyne }^{*} \sec ^{*} \mathrm{~cm}^{-5}\right)\end{array}$ & $\mathrm{Nd}$ & 343 dyne $^{*} \mathrm{sec}^{*} \mathrm{~cm}^{-5}$ & 117 dyne $^{*} \sec ^{*} \mathrm{~cm}^{-5}$ \\
\hline $\begin{array}{l}\text { Cardiac output } \\
(4-8 \mathrm{~L} / \mathrm{min})\end{array}$ & $\mathrm{Nd}$ & $4.7 \mathrm{~L} / \mathrm{min}$ & $5.2 \mathrm{~L} / \mathrm{min}$ \\
\hline $\begin{array}{l}\text { Cardiac index } \\
(2-4 \mathrm{~L} / \mathrm{min} / \mathrm{mq})\end{array}$ & $\mathrm{Nd}$ & $2.6 \mathrm{~L} / \mathrm{min} / \mathrm{mq}$ & $\mathrm{Nd}$ \\
\hline $\begin{array}{l}\text { Pulmonary wedge pressure } \\
(6-15 \mathrm{mmHg})\end{array}$ & $\mathrm{Nd}$ & $16 \mathrm{mmHg}$ & $\mathrm{Nd}$ \\
\hline
\end{tabular}

${ }^{\circ}$ Measured with a pulse oximeter; nd: not done; CRP, C reactive protein; WBC, white blood cells; sPAP, systolic pulmonary artery pressure; mPAP,mean pulmonary artery pressure.

Table 2. Pre- and post-operative spirometry (after atypical resection of left upper pulmonary lobe).

\begin{tabular}{lccccccc} 
Parameter & Unit & Ref & Pre & Pre \% Ref & Post lung resection & Var \% \\
FEV1 & Liters & 3.55 & 2.97 & 64 & 2.21 & -26 \\
\hline FVC & Liters & 4.12 & 4.25 & 103 & 3.28 & -23 \\
\hline FEV1/FVC & $\%$ & 82 & 70 & 2.08 & 46 & 67 & -4 \\
\hline FEF25-75\% & L/sec & 4.56 & 4.81 & 65 & 3.46 & -29 \\
\hline FEF25\% & L/sec & 7.43 & 2.49 & 52 & 1.77 & -28 \\
\hline FEF50\% & L/sec & 4.82 & 0.85 & 41 & 0.82 & -29 \\
\hline FEF75\% & L/sec & 2.08 & 6.03 & 69 & 3.90 & -35 \\
\hline PEF & L/sec & 8.73 & & & & -35 \\
\hline
\end{tabular}


clinical suspicion of chronic thromboembolic pulmonary hypertension was confirmed using lung perfusion scintigraphy and the right hearth catheterization (Figure 2). The mean pulmonary artery pressure at rest was $46 \mathrm{mmHg}$ (normal value $9-18 \mathrm{mmHg}$ ). The patient refused to perform an evaluation at a cardiothoracic surgery referral center at the University Hospital of Pavia, Italy. However, after six months and a further deterioration of the dyspnea he accepted to be referred to this center for a bilateral pulmonary endarterectomy. The surgical intervention was uneventful and followed by clinical and functional improvement. After three months of a cardio-thoracic rehabilitation program the patient was discharged at home. The pre- and postoperative spirometry are shown in Figure 3. After a follow-up of seven years the patient is alive and in stable conditions.

\section{Discussion}

An association between hypercoagulability and nephrotic syndrome (NS), which is characterized by heavy proteinuria, hypoalbuminemia, hyperlipidemia and edema, has been established many years ago [6,7]. This hypercoagulable state is likely caused by multiple factors, including platelet activation and aggregation, hyperfibrinogenemia, loss of antithrombin, hypoplasminogenemia and increased levels of plasminogen activator inhibitor [7]. The prevalence of pulmonary embolism in nephrotic patients has been greatly different among studies and can be asymptomatic or even lethal [6]. Although the MTHFR 677C->T polymorphism increases the homocysteine levels, the association between

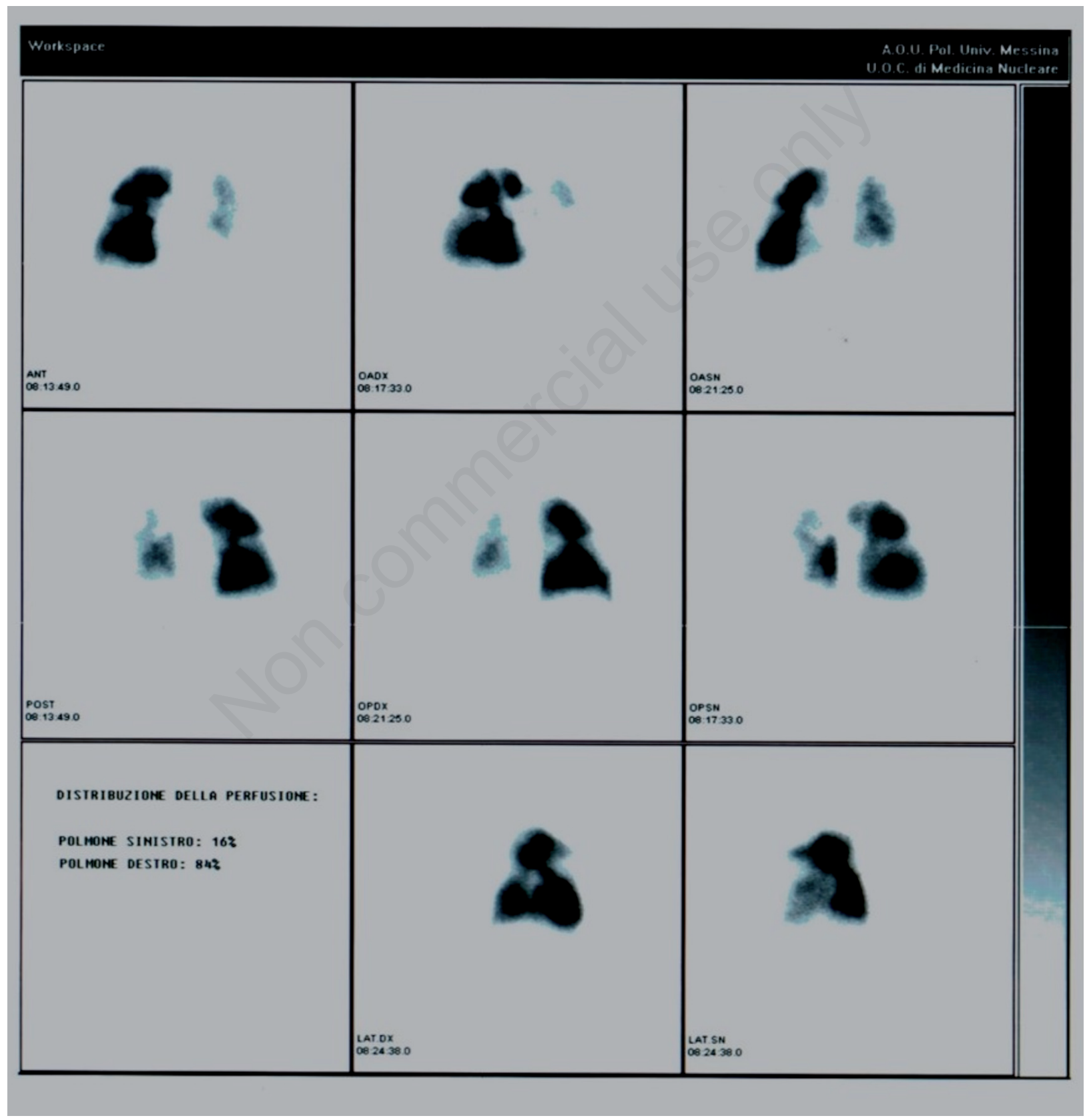

Figure 2. Lung perfusion scintigraphy. There are many perfusion defects in both lungs, partly consistent with the previous atypical resection of the upper left lobe and in other points strongly suggestive of their embolic nature. 


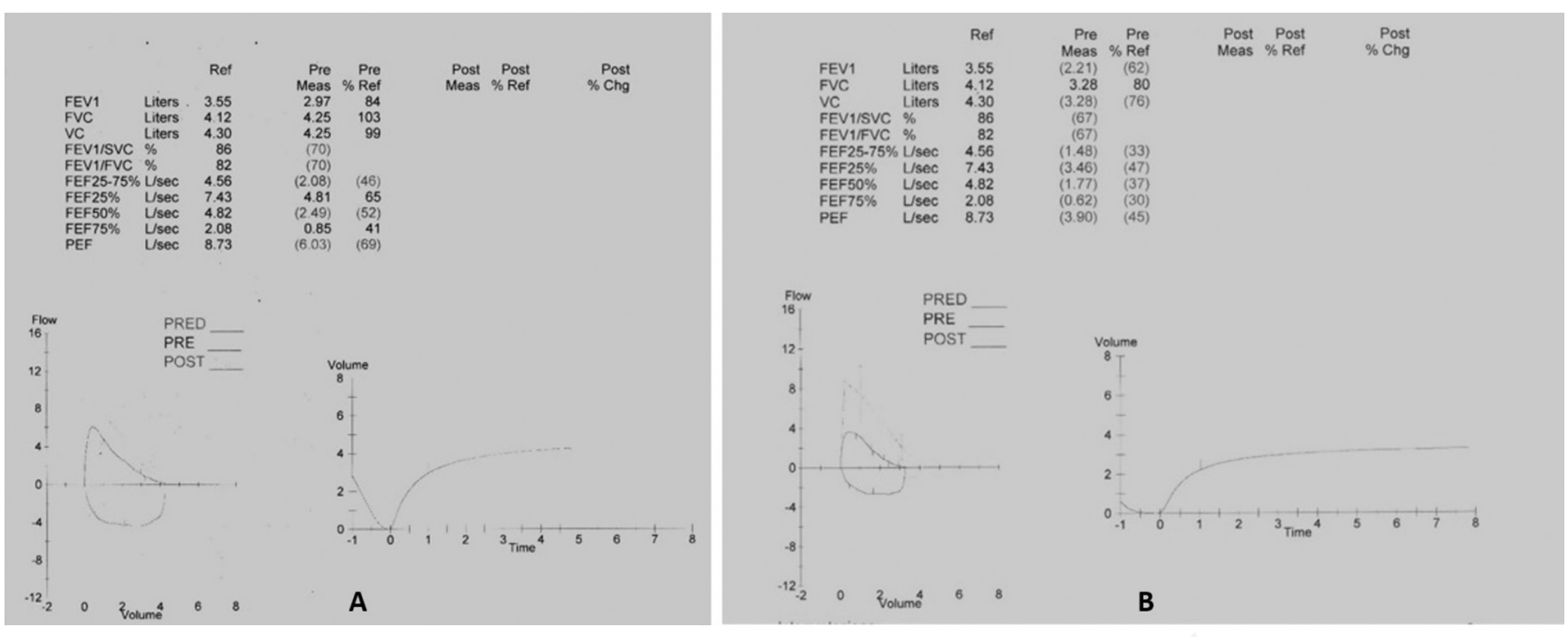

Figure 3. A) Preoperative spirometry documented a normal flow-volume curve. B) Spirometry performed after atypical resection of left upper pulmonary lobe documented a mild decrease of the vital capacity.

this polymorphism and an increased risk of pulmonary thromboembolism is controversial [3,8-10]. It is, possible that hyperhomocysteinemia led to venous thrombosis, with secondary embolism in the patient's pulmonary circulation. Vascular endothelial necrosis caused by extremely high homocysteine levels might have caused localized thrombus formation in the vascular tree. Nevertheless, duplex ultrasonography and a CT scan did not detect deep vein thrombosis in the patient's legs, abdomen or pelvis of this patient as previously demonstrated in another case report [11]. Chronic thromboembolic pulmonary hypertension (CTEPH) is a rare but life-threatening complication of pulmonary embolism and is defined as precapillary pulmonary hypertension (mean pulmonary artery pressure $\geq 25 \mathrm{mmHg}$ with a pulmonary capillary wedge pressure $\leq 15 \mathrm{mmHg}$ ) associated with mismatched perfusion defects on ventilation-perfusion lung scan and signs of chronic thromboembolic disease on computed tomography pulmonary angiogram and/or conventional pulmonary angiography, in a patient who received at least 3 months of therapeutic anticoagulation [5]. The diagnostic work-up to detect or rule out CTEPH should include ventilationperfusion scintigraphy, which has high sensitivity and a negative predictive value of nearly $100 \%$. Patients with suspected CTEPH should be referred to a specialist centre for right-heart catheterization and pulmonary angiography. Surgical pulmonary endarterectomy is still the treatment of choice for CTEPH and is associated with excellent longterm results and a high probability of cure [4].

Although several studies have shown that homocysteine levels can be reduced by vitamin supplementation, it has yet to be proven that this reduction leads to a reduced risk of cardiovascular morbidity and mortality [12].

\section{Conclusions}

In summary, we describe an unusual case of a 30 -year-old man with nephrotic syndrome from childhood and concomitant occult hyperhomocysteinemia who presented with pulmonary artery thrombosis and lung abscess that evolved in a chronic thromboembolic pulmonary hypertension successfully treated with bilateral pulmonary endarterectomy. CPEPH must be suspected in any patient with NS, with or without hyperhomocysteinemia, and unexplained dyspnea.

\section{References}

1. Kerlin BA, Ayoob R, Smoyer WE. Epidemiology and pathophysiology of nephrotic syndrome-associated thromboembolic disease. Clin J Am Soc Nephrol 2012;7:513-20.

2. Matsuda A, Tsuchiya K, Yabuki Y, et al. Fatal diffuse pulmonary arterial thrombosis as a complication of nephrotic syndrome. Clin Exp Nephrol 2007;11:316-20.

3. Mannucci PM, Franchini M. The real value of thrombophilia markers in identifying patients at high risk of venous thromboembolism. Expert Rev Hematol 2014;7:757-65.

4. Hoeper MM, Madani MM, Nakanishi N, et al. Chronic thromboembolic pulmonary hypertension. Lancet Respir Med 2014;2:573-82.

5. O'Connell C, Montani D, Savale L, et al. Chronic thromboembolic pulmonary hypertension. Presse Med 2015;44:e409-16.

6. Kayali F, Najjar R, Aswad F, et al. Venous thromboembolism in patients hospitalized with nephrotic syndrome. Am J Med 2008;121:226-30.

7. Singhal R, Brimble KS. Thromboembolic complications in the nephrotic syndrome: pathophysiology and clinical management. Thromb Res 2006;118:397-407.

8. Bezemer ID, Doggen CJ, Vos HL, et al. No association between the common MTHFR 677C->T polymorphism and venous thrombosis: results from the MEGA study. Arch Intern Med 2007;167:497-501.

9. Den Heijer M, Lewington S, Clarke R. Homocysteine, MTHFR and risk of venous thrombosis: a meta-analysis of published epidemiological studies. J Thromb Haemost 2005;3:292-9.

10. Gao L, Kolanuvada B, Naik G, et al. Hyperhomocysteinemia-induced upper extremity deep vein thrombosis and pulmonary embolism in a patient with methyltetrahydrofolate reductase mutation: a case report and literature review. Blood Coagul Fibrinolysis 2016;27:720-3.

11. 11 Goette A, Hammwohner M, Dierkes J, et al. Aortic thrombus and pulmonary embolism in a patient with hyperhomocysteinemia. Nat Clin Pract Cardiovasc Med 2006;3:396-9; quiz following 399.

12. 12 Kumar T, Sharma GS, Singh LR. Homocystinuria: Therapeutic approach. Clin Chim Acta 2016;458:55-62. 